\title{
Analysis of creation and combustion process of hydrogen-air mixtures by optical method in isochoric chamber
}

The article considers the analysis of combustion process of hydrogen-air mixture of variable composition. Direct injection of hydrogen into the isochoric combustion chamber was applied and the mixture formation took place during the combustion process. The influence of the dose distribution of the fuel supplied before and after ignition on the formation of the flame front and the course of the pressure in the isochoric combustion chamber was discussed. The filming process and registration of pressure in the isochoric chamber during research of combustion process was applied.

Key words: hydrogen-air mixture, isochoric combustion chamber, registration of pressure, filming of combustion process

\section{Introduction}

The use of hydrogen as fuel in spark-ignition engines is becoming more and more up to date due to the ecological aspects of automotive industry. The combustion product of the hydrogen-air mixture is only water vapour and nitrogen oxides, which emerge under high loads and usage of poor mixture. The availability of hydrogen as an energy carrier is also not overestimated. In the case of hydrogen is supplied into the intake duct, hydrogen-powered engines feature lower specific power output compared to gasoline-powered engines. The reason for this is the reduction of the filling factor, due to the high volume of hydrogen in the mixture because the stoichiometric constant is $2.38\left[\mathrm{Nm}^{3} / \mathrm{Nm}^{3}\right]$. Combustion anomalies may also take place during engine power supply, and there is also a risk of uncontrolled ignition in the intake duct, as the mixture with such composition has explosive characteristics. The mixture formed in the intake channel, during the filling and compressing process, is heated from the valves and from the cylinder walls and undergoes a strong swirl. These phenomena lead to increased internal and kinetic energy of hydrogen-air mixture which promotes self-ignition.

These problems can be solved by feeding hydrogen directly to the engine combustion chamber by means of an injector. The authors of the article formulated thesis that using a very high diffusion coefficient of hydrogen can initiate the ignition of the mixture by spark discharge of spark plug at the end of the injection process. Reducing the formation time reduces the degree of advancement of preignition reactions in front of the flame front, reducing the risk of combustion anomalies. During the initial motor tests, it became apparent that it is possible to form the pressure wave in the engine working space due to the desired pressure increase values $\mathrm{dp} / \mathrm{d} \alpha$. This effect depends on the initiation of ignition of part of the fuel dose, with respect to the rest of the dose delivered continuously during the combustion process. Also in this case, it was possible to regulate the engine power quantitatively and qualitatively due to the wide range of ignition of the hydrogen-air mixture.

Authors have conducted preliminary research in an isochoric chamber with the ability to record high quality pictures in high speed of frame rates and check pressure changes during the process of hydrogen-air mixture formation and combustion. The purpose of the study was to analyse the process of hydrogen-air mixture building and flame spreading depending on the method of distribution of the hydrogen dose and the initiation of combustion.

\section{Method of research}

The fixed volume chamber with the possibility of lighting and filming of its interior was used during research investigation. A pressure transducer for fast-change measurements was installed in the chamber. In addition, two manually operated valves were used to fill the chamber with air and to empty it from the exhaust. It provided the possibility of purging the chamber after each combustion cycle. In order to deliver fuel to the chamber, a standard high pressure gasoline injector was used. A spark plug was mounted into the chamber. The control system of fuel injection, ignition, pressure recording and camera was based on a specially written program in LabVIEW environment.

Figure 1 shows test bench, which the main object is a suitably equipped fixed-volume chamber, where the assumed combustion of the hydrogen-air mixture was realized.

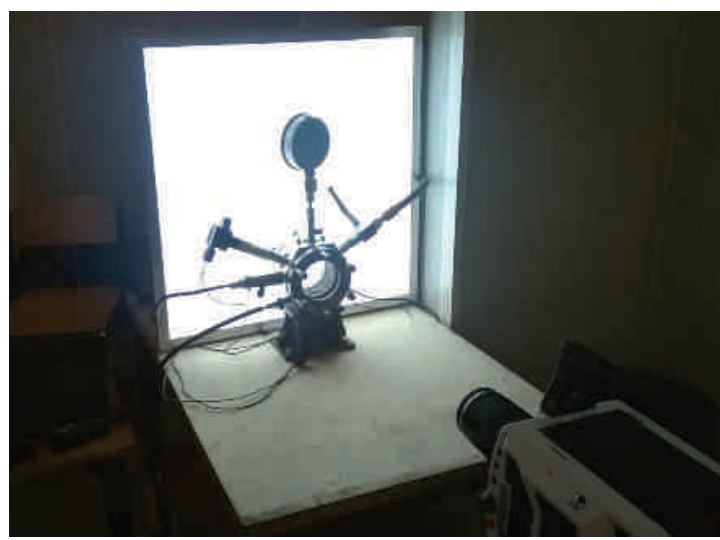

Fig. 1. Test bench with isochoric combustion chamber

Schematic diagram of a constant-volume chamber with measurement systems: video footage, control of hydrogen supply and ignition system is presented in the Fig. 2 . 


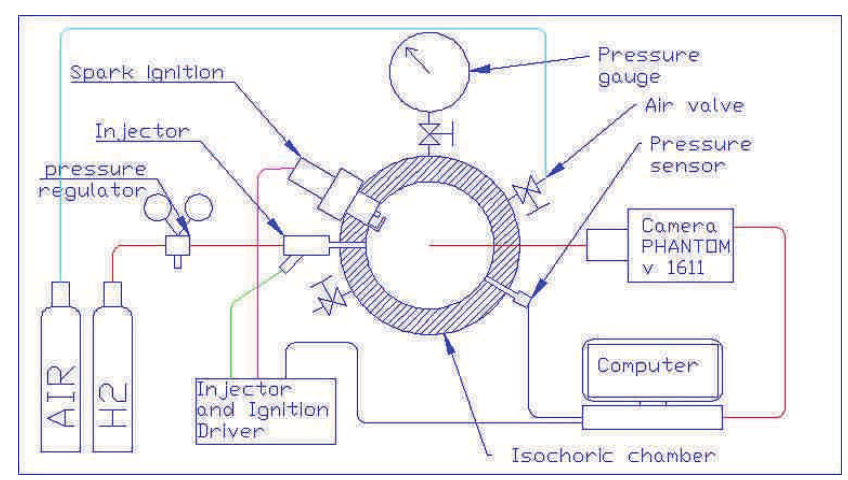

Fig. 2. Schematic diagram of the test bench

First, the amount of hydrogen supplied to the isochoric chamber was determined in one cycle. The amount of hydrogen injected per cycle was calculated using the gas state equation based on pressure variations in the chamber during one injection at a predetermined time. Hydrogen injection was applied to a chamber pre-filled with air at a pressure of $0.9 \mathrm{MPa}$. The injector was powered by hydrogen at a pressure of $5 \mathrm{MPa}$. Then the minimum dose of hydrogen injected into the test chamber was determined, which could be repeatedly initiated by the ignition spark. The research chamber was equipped with two glass windows in one axis. One window was used to illuminate the interior of the chamber and the second was to record the combustion in the chamber. Both windows are round and have a diameter of $79.5 \mathrm{~mm}$. The injector and spark plug were mounted in axes perpendicular to the optical axis of the chamber. The injector and the spark plug were a short distance from each other. The injector was installed so that the output gas flowed almost tangentially to the chamber wall, which facilitated the swirling of the charge. As an illuminator, the LED matrix was used. Such a matrix illuminated the entire interior of the chamber evenly. A PHANTOM v 1611 camera with infrared filter lens was used for filming. The resolution of the camera's matrix was $768 \times 768$ pixels, the frame rate was 20000 and the exposure was $1 \mu \mathrm{s}$. Camera was equipped by lens type Macro Planar $100 \mathrm{~mm} \mathrm{f/2}$ with infrared filter from firm Carl Zeiss. The pressure measurement system in the chamber was by the OPTRAND pressure switch, model D21283-Q equipped. Pressure measurement was done at frequency $20 \mathrm{kHz}$. Pressure and image recording, fuel injection and ignition angle were synchronized. Such type of synchronization allows assigning a pressure value to a specific frame of the movie in the time.

\section{Investigation of hydrogen-air mixtures combustion}

In the chamber pre-filled with air at a pressure of 0.9 $\mathrm{MPa}$, a hydrogen dose corresponding to a global air factor of $\lambda=1.8$ was injected for an injection time of $65 \mathrm{~ms}$ and combustion and pressure profiles were recorded. Burning was initiated when the injector was closed. The course of pressure changes in the chamber is shown in Fig. 3.
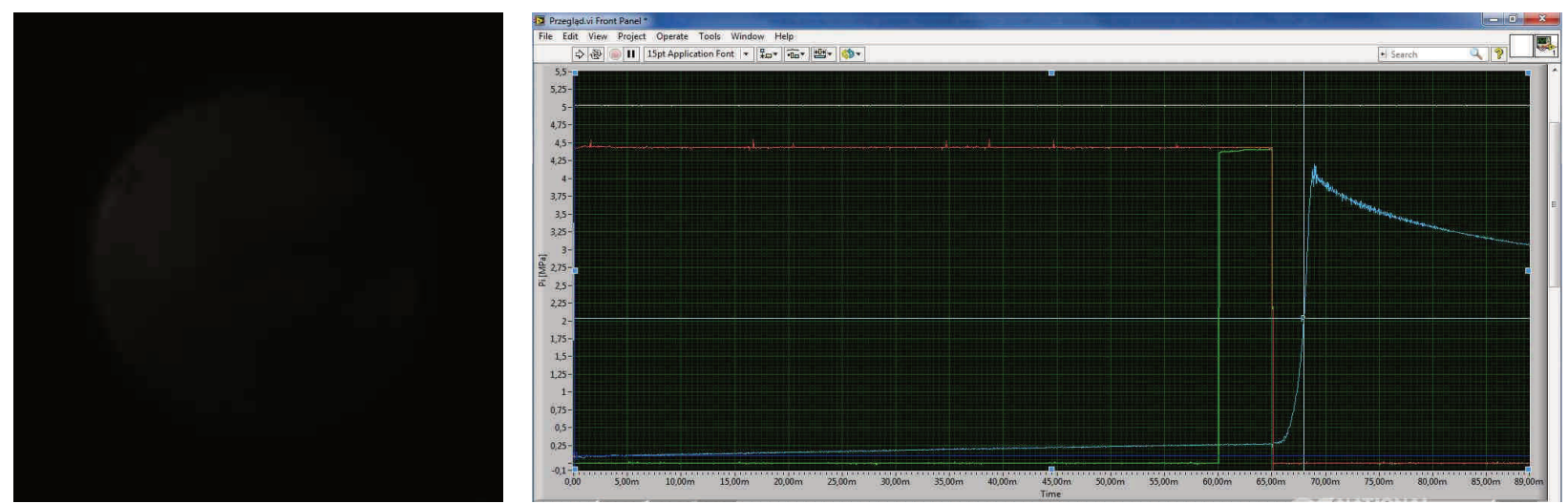

Fig. 3a. Photo of the combustion process and the pressure course with the marked pressure value. $3 \mathrm{~ms}$ after the combustion initiation
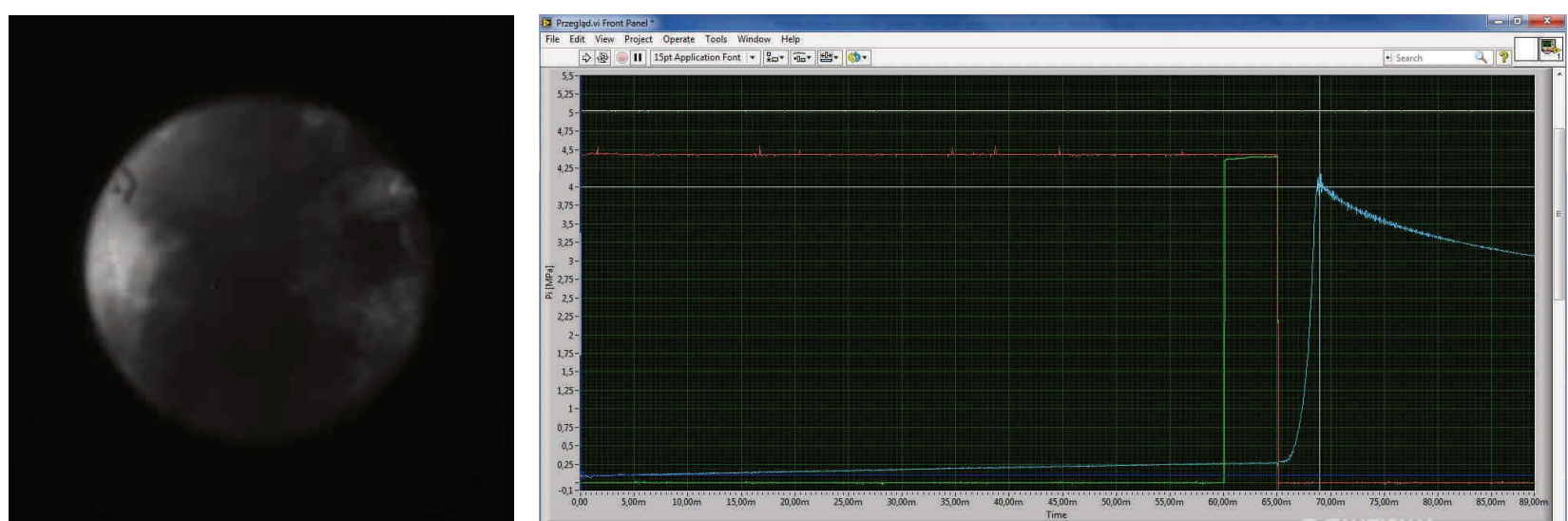

Fig. 3b. Photo of the combustion process and the pressure course with the marked pressure value $4 \mathrm{~ms}$ after the combustion initiation 
Selected photographs show the stages of combustion evolution. The blue line represents the pressure in the isochoric chamber, the green line control signal of the ignition system, and the red line control signal of the injector. The combustion firing initiation corresponds to the moment of the falling edge of the control signal in the ignition system and the high level of the injection control signal corresponds to the opening of the injector.
Then an identical amount of hydrogen was supplied to the chamber, but the combustion initiation was followed during the fuel injection process and the fuel injection was continued during the combustion of the creating mixture. Pictures taken for the selected burning initiation time one can find below (Fig. 4 and Fig. 5).
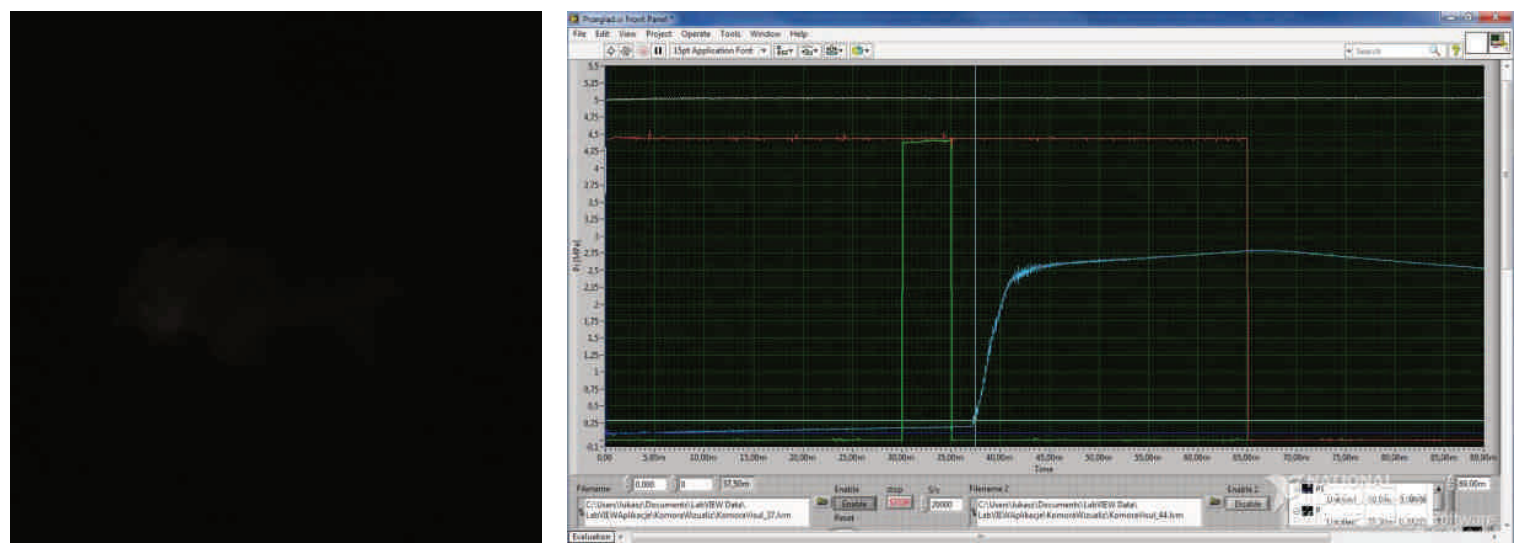

Fig. 4a. Photo of combustion advancement and pressure course with marked pressure value $2.5 \mathrm{~ms}$ after combustion initiation. Combustion initiation $-35 \mathrm{~ms}$ after opening of injector
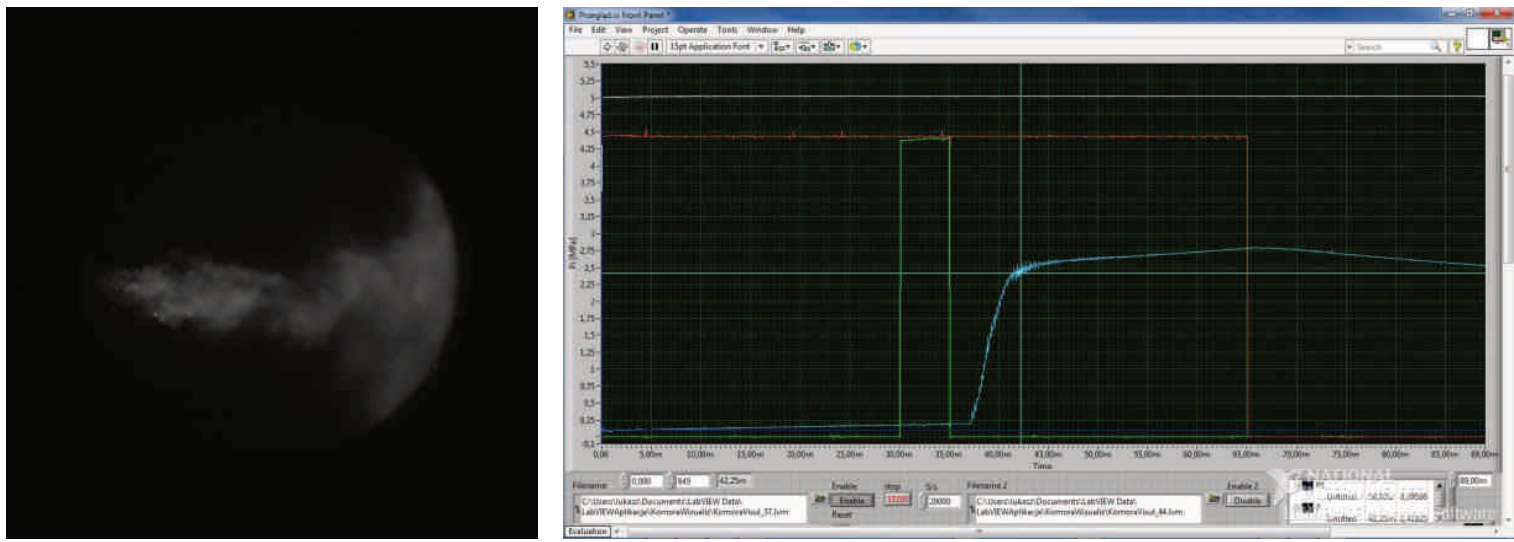

Fig. 4b. Photo of combustion advancement and pressure course with marked pressure value $7.25 \mathrm{~ms}$ after initiation of combustion. Combustion initiation $-35 \mathrm{~ms}$ after opening of injector
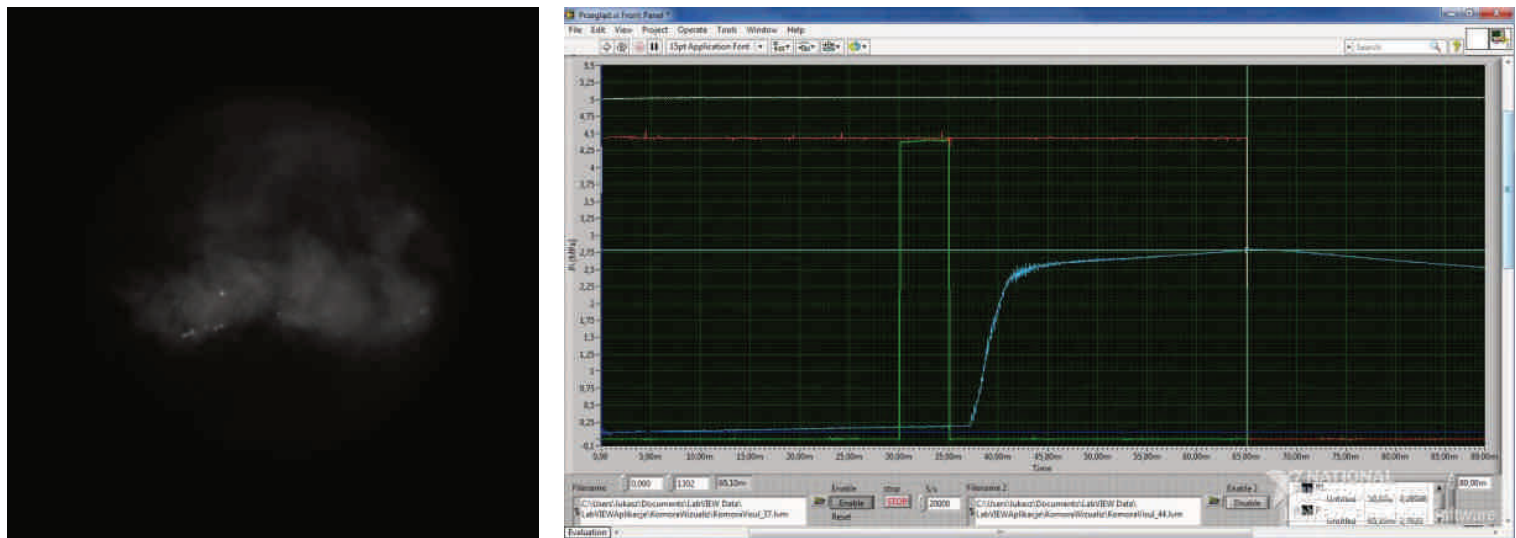

Fig. 4c. Photo of combustion progress and pressure course with marked pressure value $30.1 \mathrm{~ms}$ after combustion initiation. Combustion initiation $-35 \mathrm{~ms}$ after opening of injector 

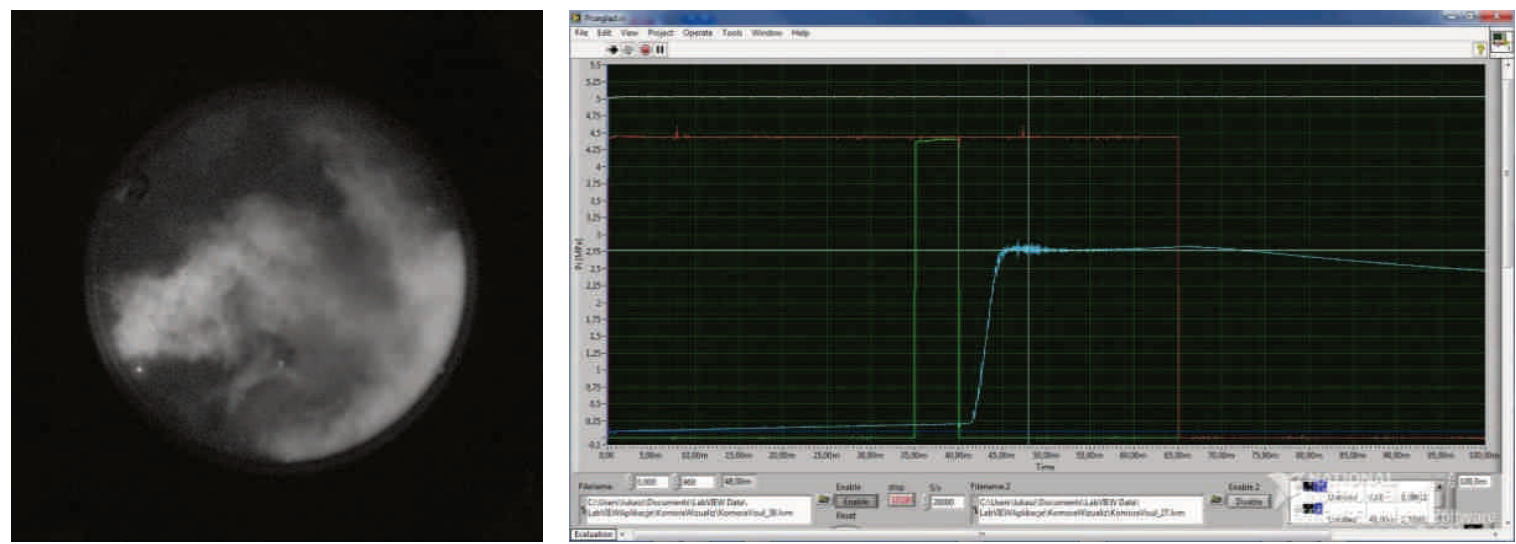

Fig. 5a. Photo of combustion progress and pressure course with marked pressure value 8ms after combustion initiation. Combustion initiation $-40 \mathrm{~ms}$ after opening of injector
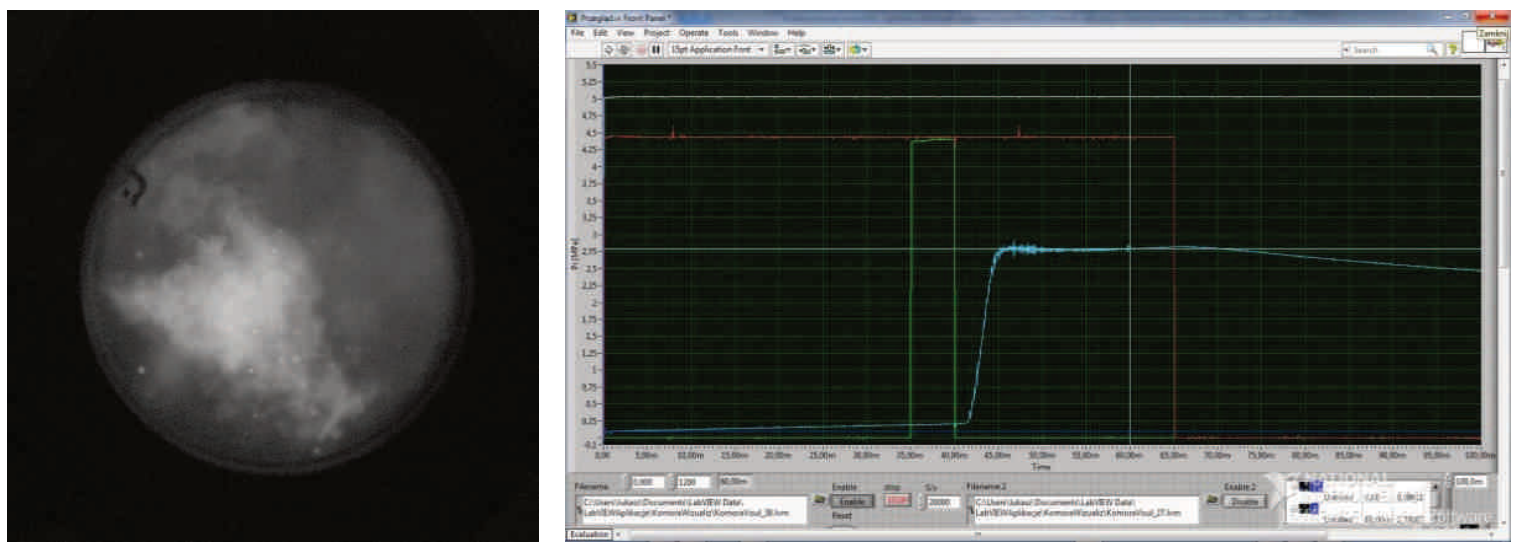

Fig. 5b. Photo of combustion stage and pressure course with marked pressure value $20 \mathrm{~ms}$ after combustion initiation. Combustion initiation -40ms after opening of injector

\section{Interpretation of research}

The use of filming as a research method was aimed at preliminary recognition of the creating and burning process of hydrogen-air mixtures. These mixtures had a various compositions and were formed during the combustion process. Some photos were dark, but at this stage of the research it was not necessary to have them processed for analysis.

The authors were also aware that the processes filmed in the isochoric chamber did not fully correspond to the actual processes taking place in the engine combustion chamber.

In case of initiation of ignition at the end of hydrogen injection into the isochoric chamber, the flame front is formed after $50 \mu \mathrm{s}$ at the spot of the spark on the spark plug electrodes, followed by rapid increase of pressure. After 3 $\mathrm{ms}$ from the injection end and the spark ignition, the pressure reaches half the maximum value. The maximum pressure is obtained after $4 \mathrm{~ms}$ from the initiation of combustion.

Figure $3 \mathrm{a}$ shows the formation of the flame $3 \mathrm{~ms}$ after the occurrence of a spark. Analysis of the film recorded during the experiment shows that the flame front spreads evenly from the spark plug into the chamber. This demonstrates the good mixing of hydrogen with air and the formation of homogeneous mixture throughout the volume of the chamber. When the peak pressure is reached, a rapid, short-term pressure change can be seen in the recorded pressure waveform. The reason for this is the reflection of the pressure wave from the wall of the chamber. This phenomenon is depicted in Figure 3b. In the case of initiation of ignition during injection $(35 \mathrm{~ms})$, when the current value of the air excess number $\lambda=3.15$, the combustion process is only visible after $2 \mathrm{~ms}$ from the moment of ignition, as shown in Figure 4a. At the same time there is also an increase in pressure. Since the fuel is still being delivered, it is seen how the fuel stream from the injector burns using the remaining oxygen in the chamber. Figure $4 \mathrm{a}$ and $4 \mathrm{~b}$ show the shape of a burning fuel stream. The burning fuel moves according to the axis of the fuel stream, which results from the construction of the injector. Figure $4 \mathrm{~b}$ shows how the flame front reaches and bounces off the wall of the chamber. This phenomenon is accompanied by significant pressure pulsations. In this case, the highest value of pressure is occurs at the end of the fuel dosing (Fig.4c).

In the case of ignition initiation $(40 \mathrm{~ms})$, when the current value of the air excess number is $\lambda=2.86$, the combustion process is visible $1.5 \mathrm{~ms}$ after the spark occurs, which means the beginning of the pressure increase and the noticeable combustion process in the video footage. The formation of the front and the shape of the flame is very similar to the one described earlier, but the geometric velocity of the flame front is greater. Reaching the front of the flame to the opposite wall of the chamber causes a strong reflection of the pressure wave and momentarily stopping the fuel flow from the injector. Figure 5a shows this situa- 
tion. Decreasing the pressure in the chamber causes the fuel to re-inject from the injector. Figures $5 \mathrm{a}$ and $5 \mathrm{~b}$ clearly show two local maxima of pressure values.

\section{Summary}

Control of the combustion process of the hydrogen-air mixture, mainly related to velocity of the flame front and heat release rat, is possible by using direct injection and initiating combustion during fuel injection. This way of initiating the combustion opens the way to supply the inter-

\section{Bibliography}

[1] WHITE, C.M., KAISER, S., ROUX, M. Fuel-air mixing in a direct injection hydrogen fueled internal combustion engine. 14th-International Symposium on Applications of Laser Techniques to Fluid Mechanics, Lisbon, .07-10 July, 2008.

[2] SUKUMARAN, S. Numerical study on mixture formation characteristics in a direct injection hydrogen engine. Iowa State University, Ames, Iowa 2010.

[3] GILLINGHAM, K. Internal combustion engine vehicles: a prudent intermediate step or a step in the wrong direction?, Stanford University Department of Management Science \& Engineering, Global Climate and Energy Project Depart-
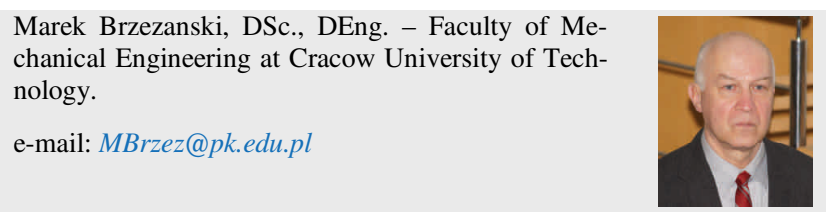

Łukasz Rodak, MEng. - Faculty of Mechanical Engineering at Cracow University of Technology.

e-mail:LRodak@pk.edu.pl nal combustion engines with a mixture of stoichiometric composition. This way, you can significantly increase the amount of heat generated by the working process without entering the combustion anomaly area. This will allow for high engine power, in comparison to engines powered by a lean mixture.

The method used to record the combustion process has proven its usefulness in evaluating mixture formation and combustion.

ment of Management Science \& Engineering, Stanford, CANADA, January 2007.

[4] WISŁOCKI, K. Studium wykorzystania badań optycznych do analizy procesów wtrysku i spalania w silnikach o zapłonie samoczynnym. Monografia habilitacyjna. Wydawnictwo Politechniki Poznańskiej. Poznań 2004

[5] WISŁOCKI, K. Optical methods in the research of internal combustion engines. Thermal Processes Research Group, Instytut Silników Spalinowych i Transportu, Politechnika Poznańska 2013.

[6] VANHAELST, R., THIELE, O., BERG, T. et al. Optical infrared-sensor inside the cylinder to determine the EGR- and residual gas rate in diesel engine. Combustion Engines. 2013, 154(3), 3-11.

Tadeusz Papuga, DEng. - Faculty of Mechanical Engineering at Cracow University of Technology.

e-mail:TPapuga@pk.edu.pl

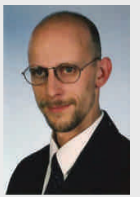

